Case Report

\title{
PULM ONARY AGENESIS-GROUP I WITH UPAA DIAGNOSED IN ELDERLY GERIATRIC AGE
}

\author{
Raghav Sharma ${ }^{1}$, Vidya Upadhyaya ${ }^{2}$,Nazir Attar ${ }^{3}$ \\ ${ }^{1}$ Professor, Department of Medicine, K.S. Hegde M edical Academy, Deralakatte, Mangalore - 575018 \\ ${ }^{2}$ Assistant Professor, Department of Radio Diagnosis, K.S. Hegde M edical Academy, Deralakatte, Mangalore - 575018 \\ ${ }^{3}$ Professor \& Unit Head, Department of Medicine, K.S. Hegde M edical Academy, Deralakatte, Mangalore - 575018 \\ Correspondence : \\ Raghav Sharma \\ Professor, Department of M edicine, K.S.Hegde M edical Academy, Deralakatte, M angalore- 575018 \\ Mobile : 9448770919 E-mail : rrsharma1967@yahoo.com
}

\begin{abstract}
:
Pulmonary agenesis and UPAA (unilateral pulmonary artery agenesis) is a rare developmental lung defect in which there is complete absence or hypoplasia of one or both lungs. It can be either isolated or associated with other congenital anomalies. The percentage of diagnosis of this condition during life has risen considerably, however it is true that more than $50 \%$ of the patients with this condition die in the first year of life. The symptoms and severity of this condition is often variable. Here with we present a male patient with left upper lo be pulmonary agenesis with left unilateral pulmonary artery agenesis (UPAA) which was detected and diagnosed for the first time at the ripe age of 70 years. Here we also review the relevant literature regarding the condition and the radiology including CT scan is described.
\end{abstract}

Keywords : Pulmonary agenesis, Agenesis of left upper lobe, Unilateral pulmonary artery agenesis-UPAA, Congenital lung malformations, CT chest.

\section{Clinical Case Profile :}

A 70 year old male person resident of a village in U.K. district of Karnataka presented to K S. Hegde Medical College hospital, Mangalore in the month of September 2011 with the complaints of fever, cough with expectoration of 12 days duration. He was apparently normal 12 days back when he developed intermittent type of high grade fever with chills and rigors. 4 days after the onset of fever he developed cough with expectoration, while sputum was minimal in amount, mucoid in consistency, non blood stained, non foul swelling and with no noticeable postural or diurnal variation. Systemic review of symptoms were non contributory.

He was treated for the same at a local hospital for 3 days with antibiotics and then was referred to K.S. Hegde college hospital for further management.

There was no history of any breathlessness, wheeze, respiratory infections in the past and he could do well all his activities as a farmer without any glitch. There was no history suggestive of any associated comorbid conditions. He was not an alcoholic or smoker but had the habit of chewing tobacco. He gave a history of asthma and treated, cured tuberculosis in his father who survived healthy up to the age of 90 years.

His general physical examination revealed a moderately built and nourished person with a height of $152 \mathrm{~cm}$ and weight of $44 \mathrm{kgs}$ with no evidence of pallor, icterus, cyanosis, clubbing or edema.. He was a febrile with pulse rate of $100 / \mathrm{min} B P .120 / 70 \mathrm{mmHg}$ and a respiratory rate of 16 breaths/ $\mathrm{min}$

His respiratory system examination revealed deviation of trachea to the left side, drooping of shoulder to the left side, supra clavicular hallowing on the left side scoliosis with concavity towards the left side. However the chest movements were equal on both sides with a chest expansion of $1 \mathrm{~cm}$, with no use of any accessory muscles of respiration. Percussion of the left hemithorax revealed a dull note over the left infraclaviuclar and left mammary areas. Auscultation revealed vesicular breath sounds with diminished intensity over the left infraclavicular and left mammary areas with crepitations, however vocal resonance (VR) being equal on both hemithorax. Other 
systems were within normal limits.

Based on symptomatology and clinical findings, provisional diagnosis of "left upper lobe pneumonia" was considered. But however there were contradicting features in the form of preserved chest movements, unaltered VF \& VR in the presence of tracheal deviation, drooping of shoulder and hollow supraclavicular region. Hence the patient and was investigated thoroughly to reach a definitive diagnosis

His investigations were asfollows:

Table 1

\begin{tabular}{|l|l|}
\hline Investigation & Patients values with normal range \\
\hline $\mathrm{Hb}$ & $12 \mathrm{gm} / \mathrm{dl}(11-15)$ \\
\hline $\mathrm{TC}($ Total count) & 11,500 cells/mm3 $(4000-10000)$ \\
\hline DC Differential count \% & $\mathrm{N}-48, \mathrm{~L}-50, \mathrm{E}-2$ \\
\hline ESR & $40 \mathrm{~mm} / \mathrm{hr}(<15)$ \\
\hline Platelet count & $2,74,000 / \mathrm{mm3}(1.5-4$ lakh) \\
\hline M PFT & Negative \\
\hline Random blood sugar & $124 \mathrm{mg} / \mathrm{dl}(70-140)$ \\
\hline Urea & $18 \mathrm{mg} / \mathrm{dl}(13-45)$ \\
\hline Creatinine & $0.7 \mathrm{mg} / \mathrm{dl}(<1.4)$ \\
\hline Total protein & $7.1 \mathrm{gm} / \mathrm{dl}(6.6-8.3)$ \\
\hline Albumin & $3.5 \mathrm{gm} / \mathrm{dl}(3.5-5)$ \\
\hline
\end{tabular}

\begin{tabular}{|l|l|}
\hline Investigation & Patients values with normal range \\
\hline Globulin & $3.6 \mathrm{gm} / \mathrm{dl}(2.3-3.5)$ \\
\hline A/G ratio & $0.9(1-1.5)$ \\
\hline Total bilirubin & $0.6 \mathrm{mg} / \mathrm{dl}(<1.0)$ \\
\hline Direct bilirubin & $0.3 \mathrm{mg} / \mathrm{dl}(<0.25)$ \\
\hline Indirect bilirubin & $0.3 \mathrm{mg} / \mathrm{dl}(<0.75)$ \\
\hline SGOT & $28 \mathrm{U} / \mathrm{L}(<40)$ \\
\hline SGPT & $29 \mathrm{U} / \mathrm{L}(<40)$ \\
\hline Alkaline phosphate & $27 \mathrm{U} / \mathrm{L}(60-170)$ \\
\hline S. Sodium & $142 \mathrm{mmol} / \mathrm{L} \quad(135-148)$ \\
\hline S. Potassium & $4 \mathrm{mmol} / \mathrm{L}(3.5-5)$ \\
\hline S. Chloride & $96 \mathrm{mg} / \mathrm{dl}(98-110)$ \\
\hline Urine routine \& microscopy & Normal \\
\hline
\end{tabular}

The investigations confirmed the diagnosis of "left upper lobe pulmonary agenesis with absent left upper lobe bronchus and absent left pulmonary artery".

Conservative management for the super added lower respiratory tract infection in the backdrop of pulmonary agenesis was delivered in the form of broad spectrum antibiotics and mucolytics. Patient was discharged on the $5^{\text {th }}$ day of admission when he was completely asymptomatic. He remained well and was asymptomatic on hisfollow-up after a gap of almost 6 months.
Table 1

\begin{tabular}{|l|l|}
\hline Special Investigations & Findings \\
\hline 12 lead ECG & $\begin{array}{l}\text { RSR }{ }^{1} \text { complex noted in V2 V3 leads } \\
\text { suggestive of right bundle branch } \\
\text { block }\end{array}$ \\
\hline Chest x-ray PA view (Fig 1) & $\begin{array}{l}\text { A veil like opacity in the left } \\
\text { hemithorax-upper zone suggestive } \\
\text { of a provisional diagnosis of left } \\
\text { upper lobeobstructive collapse }\end{array}$ \\
\hline Contrast CTchest (Fig2,3,4) & \begin{tabular}{l} 
Axial CT thorax (Fig 2) : main \\
pulmonary artery and right \\
pulmonary artery (marked by star \\
mark) well seen with hypoplastic \\
left pulmonary artery (marked by \\
arrow mark) and trans mediastinal \\
herniation of right lung (marked by \\
plusmark) are seen. \\
CTthoraxBronchus view (Fig3) \\
Agenesis of left upper lobe and \\
absent left upper lobe bronchus \\
well seen. \\
CT thorax VR image (Fig 4) : Left \\
upper lobe agenesis, absent left \\
upper lobe bronchus, hypoplastic \\
left pulmonary artery and trans \\
mediastinal herniation of right \\
lungwell seen. \\
\hline Fig5: main pulmonaryartery \\
(M PA)and right pulmonaryartery \\
(RPA) well seen w hile left \\
pulmonaryartery (LPA) is absent. \\
Fig 6: M PA,RPA seen while fibrous \\
strand evident at origin of LPA. \\
Fig 7: Blood flow in M PA,RPA and \\
absent blood flow in LPA \\
No other abnormalities in rest of \\
the cardia.
\end{tabular} \\
\hline
\end{tabular}

"The rarity of the present case is that a rare congenital condition being detected and diagnosed in a geriatric age and also it being found to be isolated with no other congenital abnormalities or facio skeletal abnormalities".

\section{Discussion :}

"Pulmonary agenesis" is a rare congenital anomaly ${ }^{1}$. Pulmonary agenesis is listed as "rare disease" by the office of rare diseases (ORD) of the national institutes of health (NIH) and also by "Ophanet" a consortium of European Partners'. Congenital lung malformations represent 5-18\% of all congenital anomalies. However this range may be an underestimate due to high frequency of undetected or asymptomatic lesions. The prevalence of pulmonary agenesis is reported to be between $0.0034 \%$ to $0.0097 \%^{3}$ 
and 1 in $3,00,000^{4}$.There is no data suggesting any apparent sex predilection for pulmonary agenesis. The etiology for the same still remains obscure ${ }^{3 .}$

Pulmonary agenesis was characterized into 3 groups by spencer initially. But presently the classification by Boyden ${ }^{5}$ is followed which is as follows:

Group 1: The lung its pulmonary artery and bronchus are absent.

Group 2: Absent lung and pulmonary artery with a rudimentary bronchus coming off the Trachea.

Group 3: Hypoplastic lung with pulmonary vessels and a fully formed bronchus.

Around $60 \%$ of cases with pulmonary agenesis do have other congenital anomalies ${ }^{6}$. Right pulmonary agenesis is associated with a higher frequency of other congenital anomalies than left pulmonary agenesis. However the cause for the same

remains unclear. Usually cardiac, gastrointestinal, genitourinary, skeletal and facial malformations are noted with pulmonary agenesis. The common congenital anomalies associated with the left pulmonary agenesis are asfollows. $^{7}$

\section{Cardiac anomalies:}

$\mathrm{G}$ Anomalous pulmonary venous drainage to azygos vein

G Persistent left superior vena cava

G PDA

G VSD

\section{Gastrointestinal anomalies:}

G Tracheoesophageal fistula

G Hiatushernia

\section{Genitourinary anomalies:}

G No particular pattern is associated with unilateral pulmonary agenesis. But when a kidney is absent, it is invariably absent on the ipsilateral side.

\section{Skeletal (ipsilateral) anomalies:}

G Thorasic vertebral anomalies and hemi vertebrae

$\mathrm{G}$ Left leg longer and thicker

$\mathrm{G}$ Thickening of cortex and bowing of left femur

G Bilateral talipes equinovarus

G Short under developed left arm

G Absent left radius

$\mathrm{G}$ Absence of left $1^{\text {st }}$ phalynxand metacarpal

$G$ Duplication of left $1^{\text {st }}$ and $2^{\text {nd }}$ phalanges

$G$ Digital positioning of thumb on left side

G Hypoplastic left sterno cleido mastoid

G Microcephaly

\section{Facial (Ipsilateral) anomalies:}

G Hypoplasia of left side of face

G Left sided mandibular hypoplasia

G Left ptosis

G Left palpebral fissure narrower

G Left earsmaller

G Deformed left external ear

$\mathrm{G}$ Accessory auricles on left side

G Cleft palate

The age of presentation of pulmonary agenesis is variable and depends on the type (group 1, 2, or 3) of lesion and also on the presence of other associated congenital anomalies.

The symptoms and severity of pulmonary agenesis is variable and may vary from completely asymptomatic to those with cardio respiratory embrrasment and recurrent respiratory infections since the early life. The most frequent symptoms encountered in patients with clinical manifestations of pulmonary agenesis are dyspnoea, tachycardia and occasionally accompanied by stridor and cyanosis. The commonest thoracic physical findings are asymmetry of the chest with respiratory lag of the affected side, which is accompanied by displacement of trachea, heart, mediastinum to the affected side with ipsilateral elevation of diaphragm. The degree of displacement varies with the degree of pulmonary agenesis.

"Diagnosing a case of pulmonary agenesis in an adult" necessitates a high index of suspicion as they are usually misdiagnosed."Pulmonary agenesis" should be suspected 


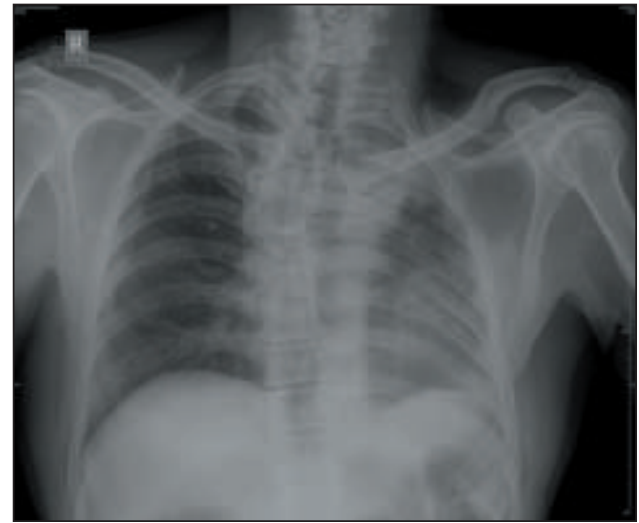

Fig 1: chest x-ray PA view

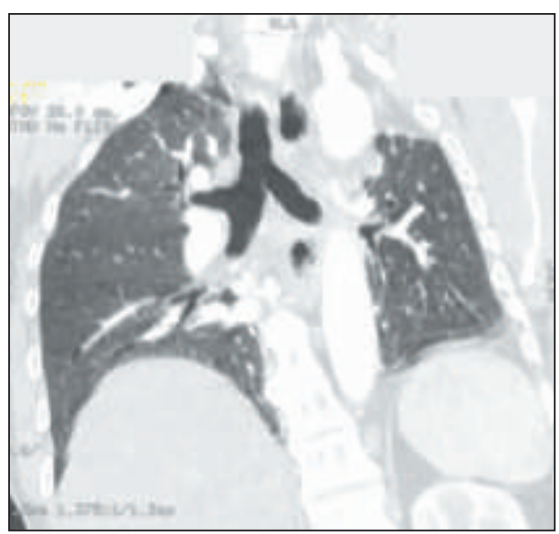

Fig 3: CT thorax bronchus view

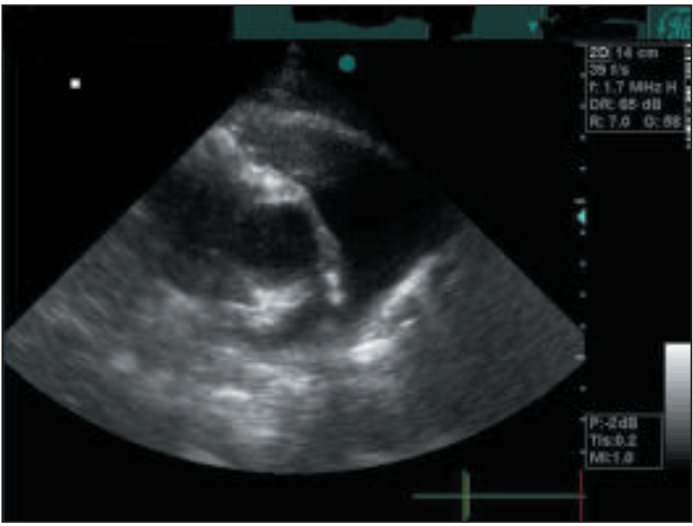

Fig 5: Echo PSX M PA RPA

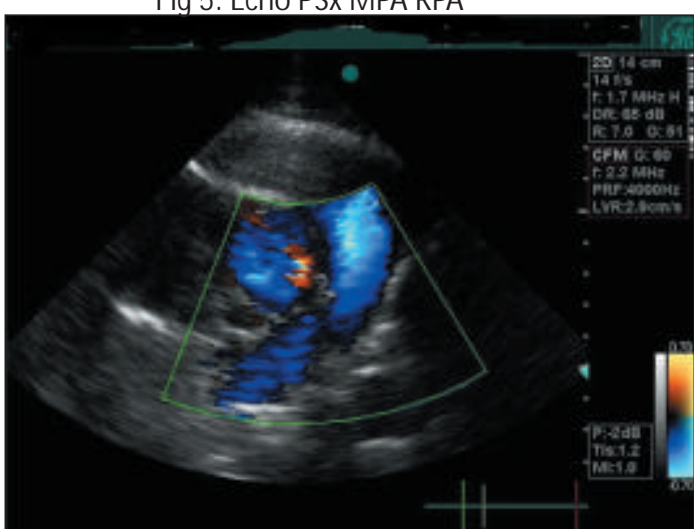

Fig 7: Echo PSX blood flow

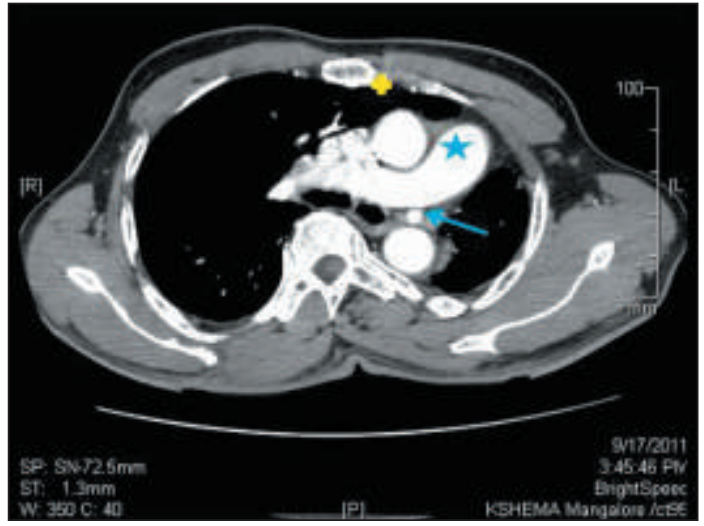

Fig 2: Axial CT thorax

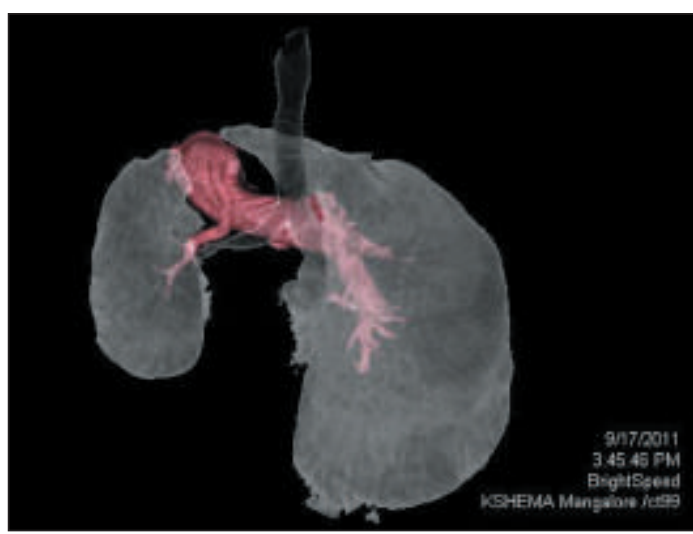

Fig 4: CT thorax VR image

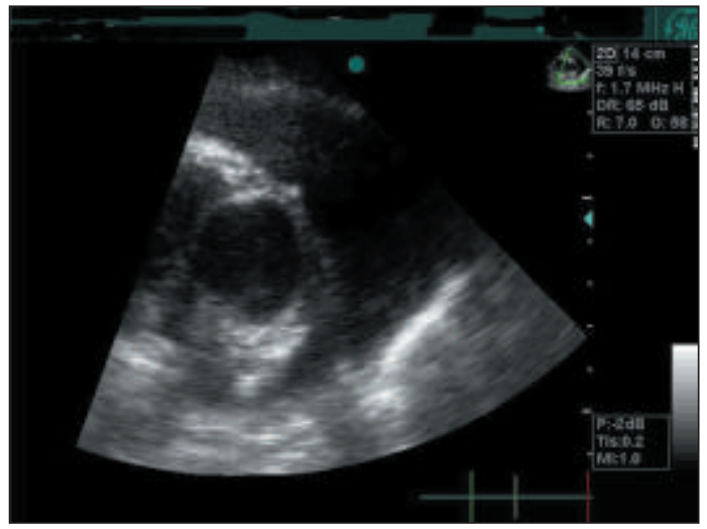

Fig 6: Echo, PSx, LPA fibrous strand

as a possible diagnosis when the chest x-ray reveals bony symmetry, opaque hemithorax, with mediastinal shift and herniation of the contra lateral lung to the affected side. After the advent of advanced investigations like CT scan and echo cardiography, the invasive procedures like pulmonary angiography, bronchography and Bronchoscopy have been rendered redundant. The CT scan (CT thorax) clearly delineates lung parenchyma with pulmonary and bronchial tree and helps to confirm the 
diagnosis of pulmonary agenesis ${ }^{8}$. Additionally Echocardiography helps to confirm the UPAA- Unilateral pulmonary artery agenesis and also detects presence of other asso ciated cardiac malformations.

Treatment of pulmonary agenesis necessitates the treatment for chest infections; however no treatment is required in asymptomatic cases. Corrective surgeries for the associated congenital anomalies may be undertaken wherever feasible.

The long term prognosis is directly related to the degree of pulmonary agenesis and the presence of comorbidities. Asymptomatic cases and occasional minimally symptomatic cases raise the expectations of good prognosis despite the

advanced age. Left pulmonary agenesis has a better prognosis than right pulmonary agenesis due to the fact of lesser incidence of other associated congenital abnormalities, lesser shift of the heart and mediastinum and lesser distortion of great vessels and airway?.

\section{Conclusions And Comments :}

The present case- "Pulmonary agenesis with UPAA reiterates the following

1. Pulmonary agenesis is very rare and may remain

\section{References :}

1. Borja AR, Ransdell HT,Villa S. Congenital developmental arrest of the lung, Ann thorax Surg 1970; 10:317-26

2. Rare diseases.info.nih.gov/GARD-genetic and rare diseases information centre.

3. Fokstunen S, Schinzel A. Unilateral lobar pulmonary agenesis in sibs, J Med Genet 2000;37:557-9

4. Kadir IS,Thekudan J, congenital unilateral pulmonary artery agenesis and aspergilloma Ann.Thorac Surg 2002; 74(6):2169-2171

5. Schaffer AJ, Pulmonary agenesis and hypoplasia. In Schaffer AJ, Avery ME eds. Disease of the new born. Philadelphia:WB Saunders, 1960:124-209. undiagnosed for many years and also frequently misdiagnosed in adult population.

2. Pulmonary agenesis with none of other congenital abnormalities (as seen in the present case) is extremely rare.

3. Diagnosing a developmental lung anomaly in a geriatric adult is a challenge for the clinician.

4. Clinicians and radiologists should always be aware of the possibility of rare congenital conditions like pulmonary agenesis even in geriatric age group and should demonstrate high index of suspicion to diagnose the same.

5. Multiple non invasive imaging modalities must be utilized to confirm the diagnosis of a rare condition like pulmonary agenesis. CT chest must be the preferred modality even before other invasive procedure like pulmonary angiography is considered.

6. Good prognosis can be expected in pulmonary agenesis with UPAA cases even despite the advanced age only if they do not suffer from recurrent respiratory infection. The best approach for these cases (as in the present case) will be close monitoring.

6. Wexels P: Agensis of lung. Thorax,6:171,1951

7. JP Booth, CL Berry, Unilateral pulmonary agenesis. Arch, Dis Childh, $1967,42,361$.

8. Mendelson DS, Hahn P, Cohen BA, Hypoplasia of the lung -CT appearance, M ount Sinaij M ed 1986; 53: 297-298.

9. Schaffer AJ, Rider AV, A note on the prognosis of pulmonary agenesis and hypoplasia according to the side affected. J Thorac Surg 1957; 33:379-82. 